\title{
DEVELOPING A METHODOLOGY FOR MEASURING READINESS IN MENTAL ILLNESS RECOVERY
}

\author{
A.J. Marques ${ }^{1}$, T. Nogueira ${ }^{2}$, C. Queiros ${ }^{2}$ \\ School of Allied Health Sciences - Porto Polytechnic Institute, Vila Nova de Gaia, ${ }^{2}$ Faculty of \\ Psychology and Educational Sciences - Porto University, Porto, Portugal
}

Introduction: Psychosocial Rehabilitation is actually understood as essential to promote the effective improvement of quality of life of mental ill people. Recovery is view process where individual plays an active role, choosing their own way. In this process, readiness is the interest, desire and motivation of the individual in his rehabilitation, being ready to change.

Aims: Develop a methodology to assess readiness of people with mental illness, and known the opinion of health professionals about this methodology.

Methods: Using the results of different studies, a methodology to assess readiness was developed and described. This description was after submitted to a focus grôsa with six professionals and to a Delphi panel of 25 professionals, all evaluating the methodology to be used with people with schizophrenia.

Results: The methodology developed includes several steps to apply with mentally ill people. The focus group discusses the methodology and the results agree with the conclusions of other studies and with theoretical constructs about this topic. The Delphi panel yields an agreement rate exceeding $90 \%$ and suggests the application of the methodology to people with schizophrenia.

Conclusions: The methodology developed to assess readiness of mentally ill people to change and define their own recovery process seems to be useful and provide a more deep understanding of individual differences linked to the process of recovery. Also seems to provide a translation into quantitative indicators and to identify the overall level of readiness, being a practical tool to support the definition of rehabilitation projects. 